\title{
Recurrent laryngeal nerve injury and hypoparathyroidism rates in reoperative thyroid surgery
}

Mohamed Benkhadoura' ${ }^{1}$ Salah Taktuk ${ }^{1}$, Reem Alobedi

\begin{tabular}{|c|c|}
\hline \multirow[t]{5}{*}{ ABSTRACT } & $\begin{array}{l}\text { Objective: Reoperative thyroid surgery is rare and has a high complication rate. This retrospective cohort study } \\
\text { was performed to determine the recurrent laryngeal nerve injury and hypoparathyroidism rates after reoperative } \\
\text { thyroid surgery in two university hospitals in Benghazi, Libya. }\end{array}$ \\
\hline & $\begin{array}{l}\text { Material and Methods: All consecutive patients who underwent reoperative thyroid surgery between January } 2002 \text { and } \\
\text { July } 2014 \text { were included retrospectively. The cohort was divided according to whether the reoperation was in the previ- } \\
\text { ously operated lobe or both lobes (ipsilateral group), or only in the previously non-operated lobe (contralateral group). }\end{array}$ \\
\hline & $\begin{array}{l}\text { Results: Of the } 73 \text { patients, } 66 \text { were female and seven were male. The median age was } 37(19-80) \text { years. Nine }(12.3 \%) \text {, five } \\
(6.8 \%) \text {, and one }(1.4 \%) \text { patient developed postoperative transient hypocalcemia, transient recurrent laryngeal nerve palsy, } \\
\text { and permanent recurrent laryngeal nerve injury, respectively. None of the patients developed permanent hypocalcemia. } \\
\text { The ipsilateral group had a higher rate of permanent recurrent laryngeal nerve injury after reoperation than the contralat- } \\
\text { eral group }(3.1 \% \text { vs. } 0 \%) \text {. It also had higher rates of transient recurrent laryngeal nerve injury }(12.5 \% \text { vs. } 2.4 \%) \text { and transient } \\
\text { hypocalcemia }(28.1 \% \text { vs. } 0 \%) \text {, but the two groups did not differ in terms of permanent hypocalcemia rates (both } 0 \%) \text {. }\end{array}$ \\
\hline & $\begin{array}{l}\text { Conclusion: Reoperative thyroid surgery is technically challenging with a high incidence of complications. The } \\
\text { ipsilateral group had more complications after reoperative thyroid surgery than the contralateral group. Hemi- or } \\
\text { total thyroidectomy at the primary surgery is recommended to reduce the frequency of reoperative thyroid surgery. }\end{array}$ \\
\hline & Keywords: Complications, completion thyroidectomy, reoperations, thyroid \\
\hline
\end{tabular}

Cite this paper as: Benkhadoura M, Taktuk S, Alobedi R. Recurrent laryngeal nerve injury and hypoparathyroidism rates in reoperative thyroid surgery. Turk J Surg 2017; 33(1): 14-17.

'Department of Surgery, Faculty of Medicine, University of Benghazi, Benghazi, Libya ${ }^{2}$ General Practitoner, Boatni Health Center, Benghazi, Libya

Address for Correspondence Mohamed Benkhadoura e-mail: khdoura@yahoo.com

Received: 07.09.2015

Accepted: 05.12.2015

(C) Copyright 2017

by Turkish Surgical Association
Available online at

www.turkjsurg.com

\section{INTRODUCTION}

While reoperation is uncommon in thyroid surgery $(1,2)$, some patients who have undergone a previous thyroid surgery for benign or malignant disease have to undergo thyroid reoperation (2). Reoperative thyroid surgery is challenging because of the scarring, edema, tissue friability, and anatomical distortion caused by the primary operation. These factors markedly increase the incidence of complications (3). The British Association of Endocrine and Thyroid Surgeons reported in 2009 that reoperative thyroid surgery is associated with a 3-fold and 2-fold increase in permanent hypoparathyroidism and permanent recurrent laryngeal nerve (RLN) palsy rates as compared to the rates after primary thyroid surgery, respectively (4). This indicates that even extensive surgical experience and a good knowledge of the normal anatomical variations of the RLNs and the parathyroid glands (which are important for reducing the postoperative morbidity after primary thyroid surgery) may not be sufficient in cases where the RLNs have a distorted anatomy due to strong postoperative adhesion or where devascularization of the parathyroid glands has occurred after the previous surgery (5).

A retrospective cohort study in Switzerland of 109 patients who underwent thyroid reoperation for disease recurrence after previous subtotal resection in 1997-2010 showed that reoperation on the previously operated lobe or both lobes (denoted as ipsilateral reoperation) is associated with a significantly higher rate of morbidity than the primary surgery, whereas this difference was not observed when reoperation was on the previously unoperated lobe (contralateral reoperation) (6).

The aim of the present study was to review our experience with reoperative thyroid surgery, to compare the results with published data, and to compare the ipsilateral and contralateral groups in terms of RLN injury and hypoparathyroidism rates.

\section{MATERIAL AND METHODS}

In total, 73 consecutive patients who underwent thyroid reoperation between January 2002 and July 2014 in two university hospitals (Benghazi Medical Center and $7^{\text {th }}$ October Hospital) in Benghazi, Libya were identified by a retrospective review of the medical records. The research was performed according to the World Medical Association Declaration of Helsinki.

All patients had undergone a single prior thyroid surgical operation. The medical history, examination results, operation details, and clinical outcomes during follow-up were recorded. The patients were di- 
vided according to whether reoperation was on the ipsilateral or contralateral lobe, as defined previously (6).

Before reoperation, the mobility of the vocal cord was determined by indirect laryngoscopy. The reoperation approach was through the scar of the previous Kocher's incision. Thereafter, the thyroid gland was reached either by splitting the strap muscles in the midline or laterally by entering between the anterior border of the sternocleidomastoid and strap muscles. The parathyroid glands and RLNs were identified intraoperatively by standard techniques. A nerve stimulator was not used in all cases because of the paucity of this device in the hospitals. None of the cases underwent intraoperative frozen-section analysis. After reoperation, indirect laryngoscopy was repeated in patients who presented with hoarseness, dyspnea, and/or reduced voice quality. Nerve palsy that continued for more than 6 months was classified as persistent RLN palsy. The diagnosis of postoperative hypocalcemia was determined clinically and/or biochemically. Symptomatic hypocalcemia was considered if any episode of symptoms or signs of hypocalcemia appeared, including tingling or numbness in the lips, hands and/or feet, Chvostek's sign, Trousseau's sign, muscle cramp, or tetany. Biochemical hypocalcemia was considered if serum calcium levels dropped below $8.0 \mathrm{mg} / \mathrm{dL}$. Symptomatic or biochemical hypocalcemia that continued for more than 6 months and required treatment was classified as persistent hypoparathyroidism. The parathyroid hormone (PTH) assay was not used to predict postoperative hypocalcemia.

All patients in both groups were followed in the surgical outpatient department for at least 6 months after reoperation and depending on postoperative endocrine status, each patient was then invited to engage in a further variable follow-up program by the endocrinologist in the endocrine clinic.

\section{Statistical Analysis}

The two groups were compared in terms of categorical variables by using Fisher's exact test. All statistical analyses were performed by using the Statistical Package for the Social Sciences (SPSS Inc.; Chicago, IL, USA), version 18.0 software program. $\mathrm{P}$ values $<0.05$ were considered to indicate statistical significance.

\section{RESULTS}

Of the 73 patients who underwent reoperative thyroid surgery during the study period, 66 were female and seven were male. The median age of the cohort was 37 (19-80) years. The most common indication for reoperation was completion thyroidectomy for well-differentiated thyroid cancer after finding malignancy in thyroid lobectomy $(n=35,48 \%)$, followed by recurrent multinodular goiter $(n=27,37 \%)$, recurrent uninodular goiter ( $n=9,12.3 \%)$, and recurrent thyrotoxicosis $(n=2,2.7 \%)$. Of the 27 patients with recurrent multinodular goiter, 21 had multinodular goiter in the previously operated side and six in the contralateral compartment. The recurrent uninodular goiter and thyrotoxicosis cases all recurred in the ipsilateral side. None of the cohort patients underwent reoperation due to recurrent thyroid cancer after primary surgery.

Thus, of the 73 patients, 41 (56.2\%) were placed in the contralateral group: all underwent contralateral thyroid lobectomy because the ipsilateral lobe had been removed at the initial thyroid surgery. Of these 41 contralateral group patients, 35 (85.4\%) and six (14.6\%) underwent lobectomy during reoperation for thyroid cancer and recurrent multinodular goiter, respectively.
Table 1. Patient characteristics, surgical indication, type of reoperation, and rates of recurrent laryngeal nerve injury and hypocalcemia in the contralateral and ipsilateral groups after reoperative surgery

\begin{tabular}{|lccc|}
\hline & $\begin{array}{c}\text { Contralateral } \\
\text { group } \\
\mathbf{n}=\mathbf{4 1}\end{array}$ & $\begin{array}{c}\text { Ipsilateral } \\
\text { group } \\
\mathbf{n}=\mathbf{3 2}\end{array}$ & $\mathbf{p}$ \\
\hline \multicolumn{2}{|c|}{ Age (years) } & $31(19-80)$ & $50.5(28-61)$ \\
\hline Sex: & male & 7 & 0 \\
& female & 34 & 32
\end{tabular}

Surgical indication:

Completion thyroidectomy

for cancer $\quad 35 \quad 0$

\begin{tabular}{|lll|}
\hline Recurrent multinodular goiter & 6 & 21 \\
\hline Recurrent uninodular goiter & 0 & 9 \\
\hline Recurrent thyrotoxicosis & 0 & 2 \\
\hline
\end{tabular}

Type of reoperation:

\begin{tabular}{|lcccc|}
\hline Lobectomy & 41 & 9 & \\
\hline Total thyroidectomy & 0 & 21 & \\
\hline Near total thyroidectomy & 0 & 2 & \\
\hline $\begin{array}{l}\text { Interval between primary } \\
\text { surgery and reoperation (years) }\end{array}$ & 1.2 & 10.1 & \\
\hline Transient RLN injury & $1(2.4)$ & $4(12.5)$ & $\mathrm{p}=0.161$ \\
\hline Permanent RLN injury & 0 & $1(3.1)$ & $\mathrm{p}=0.438$ \\
\hline Transient hypocalcemia & 0 & $9(28.1)$ & $\mathrm{p}<0.001$ \\
\hline Permanent hypocalcemia & 0 & 0 & \\
\hline $\begin{array}{l}\text { RLN: recurrent laryngeal nerve injury } \\
\text { Datas are presented } \mathrm{n}(\%) .\end{array}$ & & & \\
\hline
\end{tabular}

The remaining 32 patients (43.8\%) were placed in the ipsilateral group because all underwent reoperations to remove thyroid tissue from the ipsilateral side or both sides. Of these 32 ipsilateral group patients, 21 (65.6\%) underwent total thyroidectomy (19 for recurrent multinodular goiter and two for recurrent thyrotoxicosis), nine (28.1\%) underwent total lobectomy (all for recurrent uninodular goiter), and two (6.3\%) underwent near total thyroidectomy (both for recurrent multinodular goiter).

For the overall cohort, the average interval between the initial thyroid surgery and reoperation was 5.1 years (range, 1 month to 19 years). For the 35 patients with thyroid cancer, this interval was 53.4 days on average (range, 1-4 months). Thus, the ipsilateral group had a significantly longer interval between the primary operation and reoperation than the contralateral group (10.1 vs. 1.2 year).

The overall average duration of postoperative follow-up was 13 months (6-24 months). Nine (12.3\%) patients developed postoperative transient hypocalcemia. None developed permanent hypocalcemia. Five (6.8\%) and one (1.4\%) patient developed transient and permanent RLN injury, respectively. The ipsilateral group had a higher rate of permanent RLN injury after reoperation than the contralateral group (3.1\% vs. $0 \%$ ). It also had higher rates of transient RLN injury ( $12.5 \%$ vs. $2.4 \%)$ and transient hypocalcemia $(28.1 \%$ vs. $0 \%)$. The two groups did not differ significantly in terms of permanent hypocalcemia rates (both $0 \%$ ) (Table 1). There was no postoperative mortality in our study cohort. 


\section{DISCUSSION}

Reoperative thyroid surgery is not a harmless procedure, even in highly specialized medical centers, as it is associated with relatively high rates of permanent RLN palsy and hypoparathyroidism (5). Both of these complications can severely affect patient quality of life, and are therefore key postoperative outcomes of thyroid surgery (7).

Müller et al. (7) showed in 2001 that the risk of permanent RLN palsy is five times greater after repeat surgery for recurrent goiter than after the primary surgery, even when the operation is performed by an experienced endocrine surgeon. Table 2 shows the rate of permanent RLN injury in their study (3\%) along with the rates reported by other studies on reoperation. Five other studies reported very low permanent RLN palsy rates $(0.9 \%, 0 \%, 0 \%, 0.4 \%$, and $0.9 \%$, respectively) $(3,8-11)$. Four other studies reported intermediate rates $(1.7 \%, 1.8 \%, 1.5 \%$, and $2.5 \%$, respectively) $(1,2,5,12)$. By contrast, the studies of Wilson et al. (13), Erdem et al. (14), and Tun et al. (15) reported higher permanent RLN palsy rates of $3.1 \%, 3.5 \%$, and $4 \%$, respectively. Moreover, Seiler et al. (16) reported the permanent RLN palsy rate as $3.5 \%$ in the $1983-1990$ period and as 5.6\% in the 1991-1994 period. The greater rate in the latter period was explained by the introduction of a policy that mandated more extensive resection at the initial thyroid surgery and a more liberal approach to reoperation surgery. Eroğlu et al. (17) also reported a high permanent RLN palsy rate of $5.5 \%$ in 165 patients who underwent completion thyroidectomy. Their high permanent RLN palsy rate was explained by the fact that at the time of completion thyroidectomy, $36(21.8 \%)$ of the patients had locoregional recurrence or metastatic disease (1). Thus, in our study, the overall rate of permanent RLN injury after reoperation was comparable to those of other studies (1.4\%). Moreover, the transient RLN injury rate of $6.8 \%$ is comparable with that previously published, which ranged from $0 \%$ to $9.4 \%(9,12,15)$.

Permanent hypoparathyroidism is another dangerous and disabling complication of reoperative thyroid surgery. Three studies reported high rates of this complication $(6.6 \%, 4.4 \%$, and $4.2 \%$, respectively) $(3,12,14)$, while five others reported intermediate rates of $1.7-3.2 \%$ (Table 2$)(1,2,5,10,18)$. The remaining six studies reported negligible rates of permanent hypoparathyroidism $(0-0.5 \%$; Table 2$)(7-9,11,13,15)$. In our study, the rate of permanent hypoparathyroidism was also $0 \%$. The low rates of permanent hypocalcemia after reoperation may be due to the use of operative techniques that aim to preserve the vascular pedicle of the parathyroid glands after capsular dissection $(1,19)$.

Regarding transient hypoparathyroidism after reoperative thyroid surgery, one study reported an unusually high rate of $38.7 \%$ (3). By contrast, the remaining studies reported rates that range from $3 \%$ to $20.7 \%$ (Table 2). In our study, the rate of transient hypoparathyroidism was $12.3 \%$.

Comparison of the ipsilateral and contralateral groups in the present study revealed that reoperation on the ipsilateral side was associated with a relatively higher rate of permanent RLN palsy (3.1\%) than reoperation on the contralateral side $(0 \%)$, but the difference was not statistically significant. This is likely to be due to the greater frequency of adhesions and anatomical difficulties in ipsilateral reoperation. By contrast, the contralateral group underwent surgery on a completely virgin territory, such as that seen in primary thyroid operations: all patients in the contralateral group either had had a previous unilateral hemithyroidectomy and required reoperation for recurrent benign thyroid disease, or they had well-differentiated thyroid cancer and required completion thyroidectomy after finding malignancy in initial thyroid lobectomy.

Despite the scarring, adhesions, and the anatomical complications associated with reoperative thyroid surgery, a number of previous studies found no significant correlation between complication rate and previous surgery $(12,14)$. Gulcelik et al. (12) reported that when permanent RLN palsy and permanent hypoparathyroidism were evaluated, there was no statistically significant difference between completion thyroidectomy and total thyroidectomy for differentiated thyroid cancer. The rates for permanent RLN palsy and

Table 2. Comparison of the results in the present study with those in former studies

\begin{tabular}{|c|c|c|c|c|c|}
\hline $\begin{array}{l}\text { Author } \\
\text { (Reference) }\end{array}$ & $\begin{array}{c}\text { Number of } \\
\text { patients }\end{array}$ & $\begin{array}{c}\text { Transient } \\
\text { hypocalcemia (\%) }\end{array}$ & $\begin{array}{c}\text { Permanent } \\
\text { hypocalcemia (\%) }\end{array}$ & $\begin{array}{c}\text { Transient } \\
\text { RLN palsy (\%) }\end{array}$ & $\begin{array}{c}\text { Permanent } \\
\text { RLN palsy (\%) }\end{array}$ \\
\hline Chao et al. (1) & 115 & 5.2 & 1.7 & 2.6 & 1.7 \\
\hline Calò et al. (3) & 106 & 38.7 & 6.6 & 4.7 & 0.9 \\
\hline Lefevre et al. (5) & 685 & 5 & 2.5 & 1.2 & 1.5 \\
\hline Terris et al. (9) & 45 & 4.5 & 0 & 0 & 0 \\
\hline Hardman et al. (2) & 164 & 7.3 & 2.4 & 5.5 & 1.8 \\
\hline Teksöz et al. (10) & 263 & 8 & 2 & 2 & 0.4 \\
\hline Rudolph et al. (18) & 494 & 11.3 & 3.2 & 5.9 & 2 \\
\hline Tun et al. (15) & 25 & 12 & 0 & 0 & 4 \\
\hline Wilson et al. (13) & 32 & 9.4 & 0 & 3.1 & 3.1 \\
\hline Levin et al. (11) & 114 & 3.4 & 0 & 0.9 & 0.9 \\
\hline Peix et al. (8) & 47 & 14.9 & 0 & 4.3 & 0 \\
\hline Muller et al. (7) & 949 & 3 & 0.5 & 5 & 3 \\
\hline Gulcelik et al. (12) & 159 & 20.7 & 4.4 & 9.4 & 2.5 \\
\hline Erdem et al. (14) & 141 & 6.3 & 4.2 & 5.6 & 3.5 \\
\hline Our study & 73 & 12.3 & 0 & 6.8 & 1.4 \\
\hline
\end{tabular}


permanent hypoparathyroidism reported were $2.5 \%$ and $4.4 \%$, respectively, in the completion thyroidectomy group and $0.9 \%$ and $4.6 \%$, respectively, in the total thyroidectomy group. Erdem et al. (14) concluded that completion thyroidectomy for differentiated thyroid cancer can be done safely with a low morbidity rate that is not significantly different from that of primary total thyroidectomy when the operation is performed in specialized centers. The rates of the two most important complications, permanent RLN palsy and permanent hypoparathyroidism, were 3.5 and $4.2 \%$, respectively, in the completion thyroidectomy group, and 3.3 and $4.3 \%$, respectively, in the primary total thyroidectomy group.

Rudolph et al. (18) observed that as compared to patients who had undergone unilateral lobectomy for multinodular goiter, patients who had previously undergone subtotal thyroidectomy had a significantly higher permanent RLN injury rate ( $3.44 \%$ vs. $0.77 \%$ ). Our results are consistent with those of Kurmann et al., whose retrospective study showed no statistical difference in permanent RLN nerve injury between patients undergoing ipsilateral and those undergoing contralateral redo-surgery (3.8\% vs. $0 \%)(6)$.

The study of Rudolph et al. (18) also showed that patients who had previously undergone subtotal thyroidectomy had a significantly higher permanent hypoparathyroidism rate than patients who had undergone unilateral lobectomy $(5.1 \%$ vs. $1.5 \%)$. In the present study, however, the ipsilateral and contralateral groups did not exhibit this difference. This may be explained by the limited number of patients in our study.

Our study has some limitations. First, it is a retrospective study and has a relatively limited number of cases. The latter is due to the relative rarity of this surgical procedure. Postoperative vocal cord examinations were not done routinely. Thus, the real rate of vocal cord paralysis cannot be reported, since voice changes may not be recorded in patients with one-sided vocal cord paralysis. Furthermore, the lack of facilities such as intraoperative laryngeal nerve monitoring may also have affected the RLN outcomes especially in the ipsilateral group. Since intraoperative laryngeal nerve monitoring may reduce the morbidity of reoperative thyroid surgery, further studies assessing its ability to reduce RLN injury rates after thyroid reoperation are warranted.

\section{CONCLUSION}

Reoperative thyroid surgery is a challenging operation due to the scarring, adhesions, tissue friability, and anatomical distortion caused by the primary surgery. This is responsible for the relatively high incidence of complications after this procedure, as shown by our present study. Reoperative thyroid surgery on the ipsilateral side is associated with greater complication rates than reoperation on the contralateral side, which had not undergone previous surgery. To reduce the frequency of reoperative thyroid surgery and its complications, we recommend that hemi- or total thyroidectomy be performed at the primary surgery instead of subtotal resection.

Ethics Committee Approval: Authors declared that the research was conducted according to the principles of the World Medical Association Declaration of Helsinki "Ethical Principles for Medical Research Involving Human Subjects", (amended in October 2013).

Informed Consent: Informed consent was not received due to the retrospective nature of the study.
Peer-review: Externally peer-reviewed.

Author Contributions: Concept - M.B.; Design - M.B., S.T.; Supervision - M.B.; Resource - M.B., S.T., R.A.; Materials - S.T., R.A.; Data Collection and/or Processing - S.T., R.A.; Analysis and/or Interpretation - M.B., S.T.; Literature Search M.B., S.T., R.A.; Writing Manuscript - M.B., R.A.; Critical Reviews - S.T., M.B., R.A.

Acknowledgements: The authors would like to thank Essam S. Hussein, head of data management at Benghazi Medical Center, for help with statistical analysis.

Conflict of Interest: No conflict of interest was declared by the authors.

Financial Disclosure: The authors declared that this study has received no financial support.

\section{REFERENCES}

1. Chao TC, Jeng LB, Lin JD, Chen MF. Reoperative thyroid surgery. World J Surg 1997; 21: 644-647. [CrossRef]

2. Hardman JC, Smith JA, Nankivell P, Sharma N, Watkinson JC. Re-operative thyroid surgery: a 20-year prospective cohort study at a tertiary referral centre. Eur Arch Otorhinolaryngol 2015; 272: 1503-1508. [CrossRef]

3. Calò PG, Pisano G, Medas F, Tatti A, Tuveri M, Nicolosi A. Risk factors in reoperative thyroid surgery for recurrent goitre: our experience. G Chir 2012; 33: 335-338.

4. Vasica G, O'Neill CJ, Sidhu SB, Sywak MS, Reeve TS, Delbridge LW. Reoperative surgery for bilateral multinodular goitre in the era of total thyroidectomy. Br J Surg 2012; 99: 688-692. [CrossRef]

5. Lefevre JH, Tresallet C, Leenhardt L, Jublanc C, Chigot JP, Menegaux F. Reoperative surgery for thyroid disease. Langenbecks Arch Surg 2007; 392: 685-691. [CrossRef]

6. Kurmann A, Herden U, Schmid SW, Candinas D, Seiler CA. Morbidity rate of reoperation in thyroid surgery: a different point of view. Swiss Med Wkly 2012; 142: w13643. [CrossRef]

7. Müller PE, Jakoby R, Heinert G, Spelsberg F. Surgery for recurrent goitre: its complications and their risk factors. Eur J Surg 2001; 167: 816-821. [CrossRef]

8. Peix JL, Van Box Som P, Olagne E, Mancini F, Bourdeix O. Results of reoperations for goiter. Ann Chir 1997; 51: 217-221.

9. Terris DJ, Khichi S, Anderson SK, Seybt MW. Reoperative thyroidectomy for benign thyroid disease. Head Neck 2010; 32: 285-289.

10. Teksöz S, Özcan M, Sargan A, Bukey Y, Özgültekin R, Özyeğin A. Reoperations and morbidity in thyroid surgery. Nobel Med 2013;9:38-42.

11. Levin KE, Clark AH, Duh QY, Demeure M, Siperstein AE, Clark OH. Reoperative thyroid surgery. Surgery 1992; 111: 604-609.

12. Gulcelik MA, Kuru B, Dincer H, Camlibel M, Yuksel UM, Yenidogan $\mathrm{E}$, et al. Complications of completion versus total thyroidectomy. Asian Pac J Cancer Prev 2012; 13: 5225-5228. [CrossRef]

13. Wilson DB, Staren ED, Prinz RA. Thyroid reoperations: indications and risks. Am Surg 1998; 64: 674-679.

14. Erdem E, Gülçelik MA, Kuru B, Alagöl H. Comparison of completion thyroidectomy and primary surgery for differentiated thyroid carcinoma. Eur J Surg Oncol 2003; 29: 747-749. [CrossRef]

15. Tun M, Salekan K, Sain AH. Reoperative thyroid surgery in hospital universiti sains malaysia. Malays J Med Sci 2003; 10: 86-89.

16. Seiler CA, Glaser C, Wagner HE. Thyroid gland surgery in an endemic region. World J Surg 1996; 20: 593-597. [CrossRef]

17. Eroğlu A, Berberoğlu U, BurukF, Yildirim E. Completion thyroidectomy for differentiated thyroid carcinoma. J Surg Oncol 1995; 59: 261-267. [CrossRef]

18. Rudolph N, Dominguez C, Beaulieu A, De Wailly P, Kraimps JL. The morbidity of reoperative surgery for recurrent benign nodular goitre: impact of previous unilateral thyroid lobectomy versus subtotal thyroidectomy. J Thyroid Res 2014; 2014: 231857. [CrossRef]

19. Reeve TS, Delbridge L, Brady P, Crummer P, Smyth C. Secondary thyroidectomy: a twenty-year experience. World J Surg 1988; 12: 449-453.[CrossRef] 